\title{
Histopathological classification of non-functioning pituitary neuroendocrine tumors
}

\author{
Emilija Manojlovic-Gacic ${ }^{1}$ B Britt Edén Engström ${ }^{2} \cdot$ Olivera Casar-Borota $^{3,4}$ (C)
}

Published online: 23 December 2017

(c) The Author(s) 2017. This article is an open access publication

\begin{abstract}
Non-functioning pituitary neuroendocrine tumors do not cause endocrine symptoms related to hypersecretion of adenohypophyseal hormones and are clinically characterized by symptoms due to growing sellar tumor mass. Histopathological classification of this tumor group has always been challenging due to their heterogeneity, limited knowledge on their biology, and diverse methodological problems. We have searched PubMed database for data related to the histopathological classification of non-functioning pituitary tumors and methods for its application. Principles of the classification and grading presented in the recently released 4th edition of the World Health Organization classification of endocrine tumors have been summarized. Based on the expression of anterior pituitary hormones and pituitary specific transcription factors, gonadotroph tumors dominate within the group of clinically non-functioning tumors, followed by corticotroph type; however, other less common types of the non-functioning tumors can be identified. Assessment of tumor cell proliferation is important to identify "high-risk adenomas." A few subtypes of non-functioning tumors belong to the category of potentially aggressive tumors, independent of the cell proliferation rate. Here, we present up to date criteria for the classification of clinically nonfunctioning pituitary tumors, offer a diagnostic approach for the routine clinical use, and emphasize a need for inclusion of prognostic and predictive markers in the classification.
\end{abstract}

Keywords Non-functioning pituitary neuroendocrine tumor $\cdot$ Pituitary adenoma $\cdot$ Immunohistochemistry $\cdot$ Transcription factors

\section{Introduction}

Non-functioning pituitary adenomas (NFPAs) or, according to a recent proposal [1], non-functioning pituitary neuroendocrine tumors (NF-PitNETs) represent a heterogeneous group of tumors characterized by the lack of endocrine symptoms related to hypersecretion of adenohypophyseal hormones [2]. They are also called "silent" adenomas,

Olivera Casar-Borota

olivera.casar-borota@igp.uu.se

1 Institute of Pathology, School of Medicine, University of Belgrade, Belgrade, Serbia

2 Department of Medical Sciences, Endocrinology and Metabolism, Uppsala University Hospital, Uppsala, Sweden

3 Department of Immunology, Genetics and Pathology, Uppsala University, Uppsala, Sweden

4 Department of Clinical Pathology, Uppsala University Hospital, Uppsala, Sweden emphasizing the lack of endocrine symptoms despite the immunohistochemical expression of anterior pituitary hormones in the tumor cells, in a large majority of the tumors [2]. Even tumors associated with slightly supranormal serum hormone concentrations, but without typical symptoms related to hormone hypersecretion, have been called silent by some authors [3], although the correctness of using the term "silent" in this context may be questionable. Mechanisms behind the silencing of pituitary tumors remain unknown [4].

NF-PitNETs represent more than one-third of PitNETs, with predominance in men and increasing frequency with older age $[2,5,6]$. However, the proportion largely varies in different studies, reaching more than 50\% [7], which may, in part, reflect the methodological difficulties in the histopathological diagnostics.

Being clinically silent, NF-PitNETs are usually diagnosed at the stage of macroadenoma, although presentation as an incidentaloma is not uncommon $[5,6]$. Around $50 \%$ of the tumors infiltrate cavernous sinuses at the time 
of diagnosis, which limits radical surgery [8,9]. Even when radiologically radically removed, a significant proportion of the tumors demonstrate regrowth $[8,10,11]$. Mechanisms behind the invasive and/or recurrent growth of NF-PitNETs are largely unknown; currently, there are no good histological predictors of aggressiveness in NFPitNETs [12, 13].

In contrast to functioning PitNETs, for many of which medical treatment is well-established, pharmacological therapy of NF-PitNETs is still experimental [14], possibly due to the biological heterogeneity of these tumors.

Classification of neuroendocrine pituitary tumors has evolved from that based on the tinctorial features through classification based on immunohistochemical hormone expression and ultrastructural characteristics $[15,16]$ to the recent World Health Organization (WHO) classification, which is based on the adenohypophyseal cell lineages defined by the expression of adenohypophyseal hormones and transcription factors [2]. With the current immunohistochemical method, only around $2 \%$ of PitNETs lack signs of pituitary cell lineage differentiation, being thus classified as null-cell adenomas [17, 18]. Although improvements have been made by including more detailed immunohistochemical characterization of the tumors, omitting majority of the clinically irrelevant ultrastructural subtypes and by adding selected predictive and prognostic markers [2], WHO classification still lacks a reliable correlation between histological parameters and clinical behavior of pituitary tumors, including NF-PitNETs. In recent years, the attempt has been made to combine the histological and immunohistochemical classification with the radiological signs of invasion. Long-term follow-up in more than 400 patients identified pituitary tumors with increased proliferation and MRI- or histologically confirmed invasion as the tumors most prone to recurrence $[19,20]$.

Classification of NF-PitNETs, which has always been particularly challenging due to the methodological problems limiting their precise characterization, may contribute to: (1) Better understanding of the genesis and biology of this heterogeneous group of pituitary tumors; (2) recognition of factors involved in the invasive and recurrent tumor growth; (3) identification of histological subtypes known for their more aggressive clinical course; (4) definition of predictive markers, which can result in improvement of post-surgical follow-up, better selection of patients suitable for radiation therapy, and hopefully development of new pharmacological therapeutic strategies.

Here, we provide an update on the histopathological classification of NF-PitNETs, present the diagnostic tools required for their classification in routine work, and give an overview of the prognostic and predictive biomarkers.

\section{Principles of current WHO histopathological classification of NF-PitNETs}

The WHO classification recognizes NF-PitNETs as variants of their functioning counterparts, leaving an independent chapter only for null-cell Pit-NETs as the only type without functioning counterpart. The golden standard for the classification of PitNETs is immunohistochemistry with antibodies toward adenohypophyseal hormones, optimally in combination with pituitary-specific transcription factors, in order to define pituitary cell lineage differentiation of the tumor [2].

As for PitNETs, in general, grading of NF-PitNETs is based on three categories, comprising the most frequent "typical adenoma" and exceptional "pituitary carcinoma." The third term, "atypical adenoma," recommended by the 2004 WHO classification [15], has been abandoned due to the lack of the ability to predict aggressive behavior of PitNETs [2, 21]. Subsequently, the term "high risk pituitary adenoma" evolved, comprising PitNETs with increased cell proliferation assessed by mitotic count and Ki-67 proliferative index and signs of invasive growth evaluated by MRI and/or histology. Furthermore, the recent WHO classification defines certain subtypes of PitNETs that tend to behave more aggressively. Notably, three out of the five types of potentially aggressive PitNETs behave or may potentially behave as non-functioning: silent corticotroph, poorly differentiated Pit-1 lineage tumor, and sparsely granulated somatotroph tumor [2]. This accentuates the need for correct histological phenotyping of NF-PitNETs, which may be challenging particularly in cases with sparse or no immunohistochemical hormone expression.

Insufficient standardization of immunohistochemical procedure, the lack of reliable and specific antibodies, and problems with the interpretation of immunohistochemical stainings are still making difficulties, both in phenotyping of the tumors, particularly non-functioning ones [2, 22], and in the assessment of proliferation [2].

Molecular analyses are still not integrated in routine diagnostics of NF-PitNETs since genetic mechanisms of their genesis have not yet been clarified [23]. However, it should be kept in mind that a small proportion of tumors related to both sporadic and germ-line mutations may present as NF-PitNETs [24]. The mutation of ubiquitin-specific protease 8 (USP8), which is frequently found in corticotroph tumors associated with Cushing disease, is not observed in silent corticotroph tumors, representing a rare example of molecular genetic differences between silent and secreting variants within the same group of pituitary tumors [25]. Sporadic gain-of-function mutations of the GNAS gene coding for the Gs $\alpha$ protein occur in approximately $40 \%$ of somatotroph tumors causing acromegaly 
$[23,24]$; however, there are no systemic data on the presence of the GNAS mutations in silent somatotroph tumors. Germ-line mutations are usually associated with hormone producing PitNETs [23, 24]. In multiple endocrine neoplasia syndrome type 1 (MEN1), though, prolactinomas and non-functioning pituitary tumors are almost equally represented [24]. Another group of syndromic disorders in which non-functioning PitNETs can occur is related to mutations in the succinate dehydrogenase genes ( $S D H x)$. The SDHx mutations-associated PitNETs have been reported to demonstrate characteristic histopathological appearance with vacuolar change in the tumor cells [26].

\section{Pituitary lineage specific classification of NF-PitNETs}

NF-PitNETs are divided into eight subtypes, according to the WHO 2017 classification (Table 1), based on the immunohistochemical expression of adenohypophyseal hormones and pituitary-specific transcription factors [2].

The use of antibodies toward anterior pituitary hormones: growth hormone $(\mathrm{GH})$, prolactin (PRL), follicle-stimulating (FSH), luteinizing ( $\mathrm{LH})$, thyroid stimulating hormone (TSH), and adrenocorticotroph hormone (ACTH) is required for phenotyping of PitNETs and for recognition of potentially aggressive subtypes. Antibody toward $\alpha$-subunit of glycoprotein hormones (TSH, FSH, LH) may be useful in cases with sparse hormone expression $[2,15]$.

Differentiation of the three main cell lineages in adenohypophysis is mediated by transcription factors [27], which are also retained in the tumors, both silent and functional, showing differentiation toward the adenohypophysial cells. Three of the pituitary specific transcription factors are recommended in routine diagnostics: pituitary transcription factor 1 (Pit-1), steroidogenic factor 1 (SF-1), and T-box family member TBX19 (T-Pit) [2, 22] (Fig. 1).

Pit-1 plays a role in the differentiation of somatotroph, lactotroph, and thyrotroph cells and respective tumors [28], including the plurihormonal variants [29]. Good-quality Pit-1 antibodies for immunohistochemistry are available.

SF-1 acts as transcription factor for differentiation of gonadotroph cells. Subsequently, it is expressed in gonadotroph PitNETs, both in silent and rare clinically functioning tumors [30]. Monoclonal anti-SF-1 antibody (clone N1665) has usually been used, albeit with inconsistent results.

T-Pit is required for the transcription of proopiomelanocortin (POMC), the precursor polypeptide to ACTH [31, 32], being a marker of corticotroph differentiation. A novel purified polyclonal antibody toward T-Pit has recently been published and is expected to be available soon [18].

Although a complete antibody panel will still be required for precise classification and for characterization of some unusual types of PitNETs, some authors propose the use of

Table 1 Histopathological types of NF-PitNETs with diagnostic and potential prognostic/predictive immunohistochemical markers

\begin{tabular}{|c|c|c|c|c|}
\hline NF-PitNET type & Transcriptional factor & Hormone staining & LMWCK & $\begin{array}{l}\text { Prognostic/ } \\
\text { predictive } \\
\text { markers }\end{array}$ \\
\hline Gonadotroph & SF-1 (GATA-2, ER $\alpha$ ) & $\beta$-FSH, $\beta$-LH, $\alpha-S U$ & Variable & ER $\alpha$, SSTRs \\
\hline Corticotroph $^{\mathrm{a}}$ & T-Pit & ACTH & Diffuse & \\
\hline Type 1 (densely granulated) & T-Pit & Diffuse, strong ACTH & Diffuse & \\
\hline Type 2 (sparsely granulated) & T-Pit & Weak, patchy ACTH & Diffuse & \\
\hline Crooke-cell & T-Pit & Periphery of the cell & Ring-like & \\
\hline Somatotroph & Pit-1 & $\mathrm{GH}$ & & SSTRs \\
\hline Sparsely granulated ${ }^{\mathrm{a}}$ & Pit-1 & Diffuse, strong & Fibrous body & \\
\hline Densely granulated & Pit-1 & Weak, patchy & Diffuse & \\
\hline Thyrotroph & Pit-1 (GATA-2) & TSH, $\alpha-\mathrm{SU}$ & Variable & SSTRs \\
\hline Lactotroph & Pit-1 (ER $\alpha)$ & PRL & Variable & \\
\hline Sparsely granulated & Pit-1 (ER $\alpha)$ & Perinuclear, Golgi zone PRL & Variable & \\
\hline Densely granulated & Pit-1 $(E R \alpha)$ & Diffuse PRL & Variable & \\
\hline Acidophilic stem cell adenoma & Pit-1 (ER $\alpha)$ & Focal and variable PRL, GH & $\begin{array}{l}\text { Fibrous body } \\
\text { (inconsistent) }\end{array}$ & \\
\hline Plurihormonal Pit- $1^{\mathrm{a}}$ & Pit-1 & GH, PRL, TSH, $\alpha-S U$ & Variable & \\
\hline Null-cell & None & None & Variable & \\
\hline Double/triple NF-PitNET & More than one & Variable & Variable & \\
\hline
\end{tabular}

Increased proliferation and MRI-confirmed invasion are criteria for high-risk adenoma in all types. MGMT is a potential predictive marker for response to temozolomide in aggressive PitNETs of all types

${ }^{a}$ NF-PitNET types with potential aggressive biological behavior 

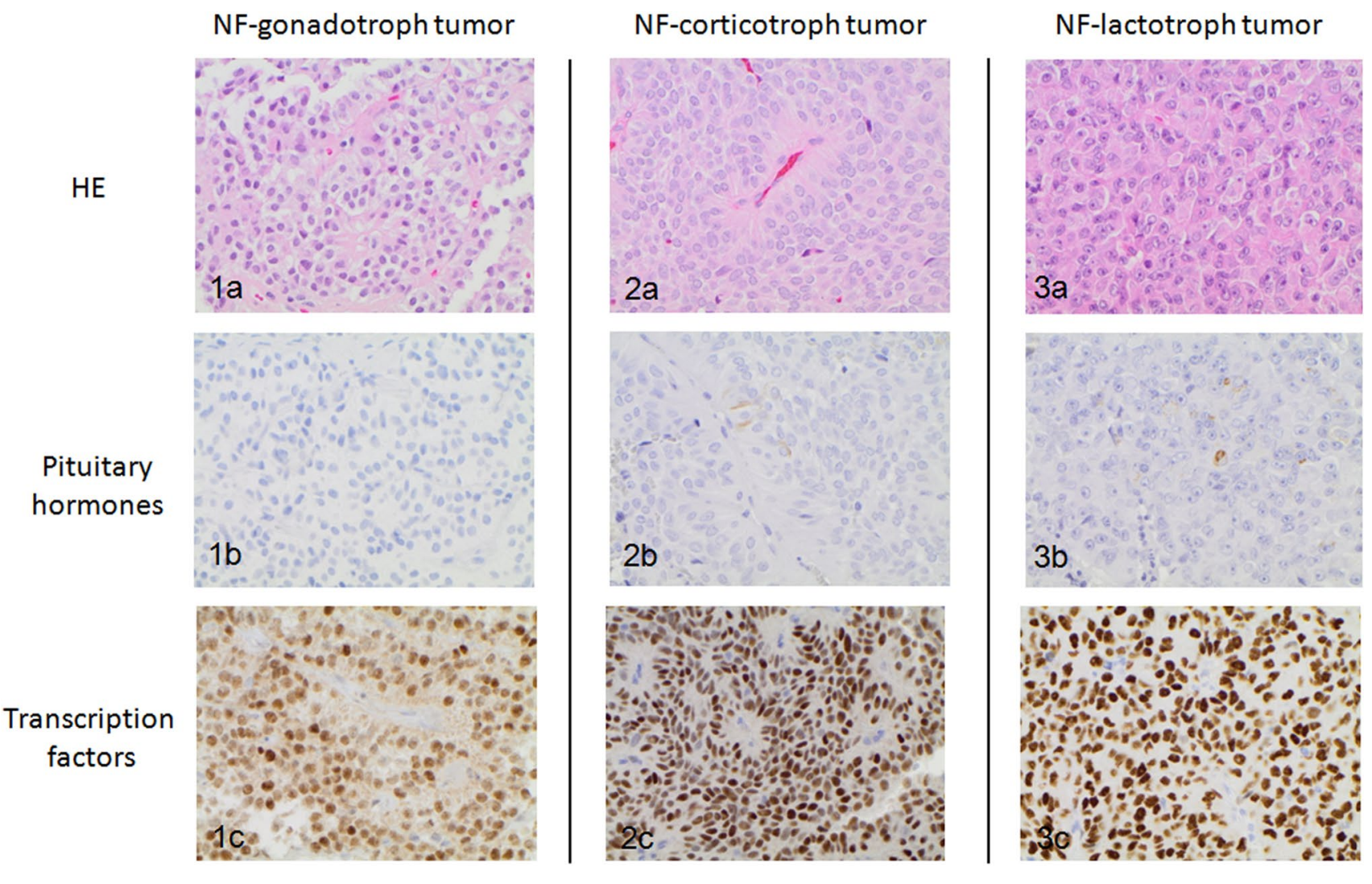

Fig. 1 Importance of pituitary transcription factors in PitNETs with sparse or no hormone-immunolabeling: NF-gonadotroph tumor 1a hematoxylin eosin staining $\mathbf{1 b}$ negative immunolabeling for gonadotroph hormones (FSH and LH) 1c nuclear expression of SF-1; NF- corticotroph tumor 2a hematoxylin eosin staining $\mathbf{2 b}$ sparse ACTH expression 2c nuclear expression of T-Pit; NF-lactotroph tumor 3a hematoxylin eosin staining 3b sparse expression of prolactin 3c nuclear expression of Pit-1 (Magnification x400) transcription factors as the first line of immunohistochemical screening of PitNETs, especially in the laboratories with high workload [22].

Although not used routinely, estrogen receptor $\alpha(E R \alpha)$ and guanine-adenine-thymine-adenine binding protein 2 (GATA-2) are also recognized as transcription factors involved in the differentiation of gonadothroph, lactotroph, and thyrotrops cells, and their respective tumors [2, 27, 33, 34].

\section{Subtypes of NF-PitNETs}

Non-functioning/silent gonadotroph tumors are SF-1 cell lineage derived tumors that typically demonstrate at least focal immunolabeling for $\beta$-FSH, $\beta$-LH, and $\alpha$-subunit [2]. Despite the methodological difficulties related to suboptimal quality of the available anti SF-1 antibodies, the nuclear labeling can usually be detected in a significant proportion of tumor cells, enabling the diagnosis in cases with sparse or no gonadotroph hormone expression [22]. Gonadotroph tumors comprise almost $80 \%$ of NF-PitNETs, when both antibodies toward gonadotroph hormones and
SF-1 are used in classification [18, 35]. However, they have been underestimated and usually classified as null cell adenomas in previous studies, in which transcription factors were not available [36, 37]. It is the only type of PitNET where the non-functioning form dominates [38, 39].

Non-functioning/silent corticotroph tumors are T-Pit lineage related tumors, usually with sparse ACTH expression without clinical evidence of Cushing disease [2, 40, 41]. They constitute about $15 \%$ of NF-PitNETs, thus, representing the second largest group of these tumors [18, 39]. The proportion of silent corticotroph tumors among NF-PitNETs is expected to increase with greater use of immunohistochemistry with anti-T-Pit antibody allowing for identification among the tumors with sparse or no ACTH expression [18]. Similar to their functioning counterparts, silent corticotroph tumors can be morphologically and ultrastructurally subdivided into densely and sparsely granulated [2, 42]. Rarely, Crooke-cell adenoma with a typical perinuclear ring-like accumulation of cytokeratin and relocation of ACTH positivity to the sub-membranous zone can manifest as clinically silent [41, 43]. Transformation of silent corticotroph tumors 
into functioning PitNET (or, exceptionally, vice versa) has been comprehensively analyzed in corticotroph tumors [40, 44-46]. However, the mechanisms remain unclear despite several potential explanations [40, 47-49]. Independently of their morphological variants, silent corticotroph tumors are recognized as tumors with the more aggressive clinical behavior due to their tendency for invasive growth, apoplexy, and recurrences [2, 40, 50, 51].

Non-functioning/silent somatotroph tumors are Pit-1 and GH immunoreactive tumors without clinical signs of acromegaly $[2,52,53]$. They represent $2-3 \%$ of all pituitary tumors [53]. Similar to their much more frequent functioning counterparts, they can be divided into sparsely and densely granulated somatotroph tumors based on low molecular weight cytokeratin (LMWCK) [CK7/8 (Cam5.2) and CK18] staining, demonstrating either fibrous bodies or diffuse cytoplasmic pattern (Table 1) [2, 53]. NF-somatotroph PitNETs are predominantly sparsely granulated, in contrast to functioning somatotroph PitNETs, where the frequency of sparsely and densely granulated tumors is equal $[52,53]$ or in favor of densely granulated subtype $[54,55]$. They have a lower proportion of GH-immunoreactive cells, which suggests lower differentiation. Majority of silent somatotroph tumors co-express prolactin [53]. Sparsely granulated somatotroph tumors are, according to the WHO classification [2], designated as more aggressive tumors based on several studies demonstrating that they are usually larger and more invasive compared to the densely granulated subtype [54-56]. In patients with acromegaly, the sparsely granulated somatotroph tumors are less responsive to somatostatin analogues, probably due to the lower expression of somatostatin receptors (SSTRs) [55].

Non-functioning/silent lactotroph PitNET are PRLimmunoreactive tumors with no clinical signs of hyperprolactinemia, apart from elevated prolactin levels due to the stalk effect [57]. In addition to transcription factor Pit-1, they also express estrogen receptor alpha [2]. Pure silent lactotroph tumors are exceptional. More often, prolactin is co-expressed with GH in Pit-1 positive tumors. Silent lactotroph tumors are very rare in surgical, but not in autopsy series [37, 58]. Both silent and functioning lactotroph tumors are sub-classified into sparsely granulated, demonstrating Golgi-like prolactin immunoreactivity and densely granulated with diffuse cytoplasmic expression of prolactin in the tumor cells [2]. Acidophil stem-cell adenoma has only been exceptionally described in silent form [37]. More aggressive behavior of the functioning lactotroph tumors in men seems to correlate with the lower expression of ER $\alpha$ compared with the lactotroph tumors in women [33]. However, the expression of ER $\alpha$ and its correlation with the clinical characteristics of silent lactotroph tumors is still obscure. Rare silent lactotroph tumors is important to identify, as addition of dopamine agonists may be considered in the treatment, although the effects are less well documented than in the clinically-functioning prolactinomas [59].

Non-functioning/silent thyrotroph tumors belong to Pit-1 lineage tumors and express $\beta$-TSH without clinical and biochemical signs of central hyperthyroidism [2, 60, 61]. They seem to occur with slightly higher frequency than their rare functioning counterparts [62, 63]. Silent and functioning thyrotroph tumors behave in a similar manner regarding the recurrence rate and time from surgery to the recurrence [62]. Non-functioning thyrotroph tumors rarely change its endocrine activity, transforming into functioning thyrotroph PitNET [35, 64].

Null-cell PitNETs are defined by the lack of immunohistochemical evidence of differentiation toward any anterior pituitary cell, using antibodies to adenohypophysial hormones and transcription factors [2]. They comprise only a few percent of all pituitary tumors [18]. However, their frequency has frequently been overestimated due to suboptimal immunohistochemical protocols and lack of reliable antibodies to pituitary-specific transcription factors. Further investigations are needed to elucidate whether nullcell adenomas really exist, or whether this category just reflects methodological limitations in the current diagnostic procedure. Since null-cell adenomas are the diagnosis of exclusion, they may sometimes pose the challenge in differential diagnosis with other, non-adenohypophysial neuroendocrine tumors of the sellar region [65].

Plurihormonal poorly differentiated Pit-1 positive tumors (previously designated as "silent subtype 3 adenoma") are rare tumors composed of large polygonal or spindle shaped cells, with atypical nuclei, sometimes containing inclusions, so called nuclear spheridia that can be observed on routine HE stains or, more readily, on electron microscopy [29, 66-68]. They may demonstrate variable and patchy immunoreactivity for GH, PRL, and TSH in different combinations. Although traditionally categorized as silent, plurihormonal Pit-1 positive tumors are associated with clinical signs of hypersecretion of Pit-1 lineage hormones in about $30 \%$ of the cases [29]. The correct diagnosis of this uncommon type of NF-PitNETs is important since it belongs to the group of potentially aggressive tumors, usually macroadenomas with propensity to invade cavernous sinus and clivus and to recur [2, 29, 66, 68].

Double/triple pituitary tumors are very rare tumors composed of demarcated components originating from different cell lineages, which can be confirmed by expression of more than one pituitary specific transcription factors. In the same tumor, silent and hormone-secreting components may be present [2]. Based on sporadic reports and small series, double/triple pituitary tumors seem to be clinically active in the majority of cases [69]. Combination of two 
or three NF PitNETs has been more frequently reported in autopsy material, suggesting that some tumors have been clinically silent $[58,70]$.

\section{Prognostic markers of NF-PitNETs}

\section{General prognostic markers for grading of NF-PitNETs: mitotic count, Ki-67 index, p53}

\section{Mitotic count}

Cell proliferation is an important prognostic marker in neuroendocrine tumors in general [71]. The prognostic significance of mitotic count in pituitary neuroendocrine tumors cannot be overestimated [19, 20]. Thorough assessment of the mitoses throughout the surgical specimen is highly recommended $[2,19,20]$, with special focus on the areas with hot-spot Ki-67 immunoreactivity, when present [2].

\section{Ki-67 proliferative index}

The Ki-67 assessment by using immunohistochemistry usually with monoclonal MIB1 antibody is mandatory for the assessment of proliferation. It seems that Ki-67 does not differ significantly between hormone-secreting and nonsecreting pituitary tumors [72]. Methodological problems, interpretational difficulties, and use of different cut-off values in different studies $[73,74]$ may explain why the interpretation of $\mathrm{Ki}-67$ has recently been reformulated, moving from the cut-off of $3 \%$ in the previous WHO classification of pituitary tumors [15] to the estimation of the percentage of Ki-67 positive nuclei without precise cut-off in the 2017 WHO classification [2]. Studies on NF-PitNETs revealed that proliferative $\mathrm{Ki}-67$ index remains the second parameter in the prediction of recurrence, after invasion of surrounding structures [75].

Proliferative Ki-67 index and mitotic activity should be estimated carefully in apoplectic PitNETs, since proliferation of inflammatory cells and cells surrounding necrosis should not be interpreted as proliferation of tumor cells. In this situation, proliferation should be evaluated in the well-preserved tumor areas, if possible, and use of additional immunolabeling with a lymphocytic marker should be considered to estimate the proportion of inflammatory cells among the Ki-67 reactive cells.
Tumor suppressor gene $\mathrm{p} 53$ as a marker of proliferation in PitNETs

Even though mutation of p53 is very rarely detected in sporadic PitNETs [76], its nuclear accumulation detected by immunohistochemistry suggested potential aggressive behavior of pituitary tumors in previous studies [77], which resulted in inclusion of p53 among the criteria for the classification of "atypical adenoma" in the previous WHO classification [15]. Nevertheless, there is still no clear consensus about its interpretation in pituitary tumors, including nonfunctioning ones [78, 79].

Bearing in mind that none of the above markers of proliferation has been proved to be prognostic independently, their combination was verified to be prognostic, particularly when associated with invasive tumor growth $[19,20]$.

\section{Additional potential prognostic markers in NF-PitNETs: ERa, E-cadherin, MGMT}

Correlation between ER $\alpha$ and invasiveness in NF-PitNETs has been reported in a previous study [80]. Recently, absence of $E R \alpha$ was found to correlate with the rate of postoperative radiotherapy or surgical re-intervention in men with NFPitNETs [35].

Role of E-cadherin, a marker of epithelial differentiation, in the invasiveness of NF-PitNETs is still unclear, despite an earlier study that could not demonstrate the correlation between E-cadherin expression and cavernous sinus invasion of NF-PitNETs [36].

Prognostic value of $O$-6-methylguanine-DNA methyltransferase (MGMT) is still controversial. In a recent metaanalysis, lower immunohistochemical expression of MGMT was associated with recurrence of PitNETs regardless of the functional status of the tumors [81].

More studies are needed before these additional prognostic markers may find their place in routine practice and eventually in the classification of NF-PitNETs.

\section{Specific prognostic categories of NF-PitNETs}

WHO classification recognizes five categories of pituitary adenomas that are shown to be more clinically aggressive regardless of their histological grading: sparsely granulated somatotroph adenomas, lactotroph macroadenomas in men, Crooke cell adenoma, silent corticotroph adenomas, and plurihormonal Pit-1 positive adenoma [2]. One of them, silent corticotroph tumor, behaves as clinically non-functioning and two of them, plurihormonal Pit-1 lineage tumor and sparsely granulated somatotroph tumor, may potentially be clinically silent. 


\section{Non-functioning pituitary carcinomas}

Metastasizing Pit-NETs or pituitary carcinomas are exceptional, and majority of them are hormone-secreting. However, non-functioning pituitary carcinomas of gonadotroph, corticotroph, or null-cell type have occasionally been reported. NF-pituitary carcinomas may also be underdiagnosed as their metastases can remain asymptomatic for years $[82,83]$.

\section{Potential predictive markers (somatostatin receptors, dopamine receptor, MGMT, MSH)}

As no medical treatment is available so far for patients with NF-PitNETs, recognition of markers that potentially could predict a response to established or novel therapies is much needed.

SSTRs, particularly type 3 and to lesser degree types 2 and 5, are expressed in gonadotroph tumors and may thus represent potential target of multireceptor somatostatin analogues such as pasireotide in patients with aggressive NF-PitNETs [35, 84, 85].

Dopamine receptors have been demonstrated on mRNA level in NF-PitNETs [86]. In a recent study, no correlation was found between DR2 protein and mRNA expression and response to treatment in patients with NF-PitNETs who received dopamine agonists aiming to prevent tumor growth after the surgery [87]. Immunohistochemical studies on DRs are unfortunately few due to the methodological difficulties related to anti-DR-antibodies.

Lower MGMT expression assessed by immunohistochemistry was found to correlate with better response to temozolomide in a study of 24 patients with aggressive PitNETs and pituitary carcinoma, of which five had aggressive NF-PitNET [88]. However, the results regarding MGMT as a predictor of temozolomide effect in pituitary tumors are still contradictory [89, 90].

DNA mismatch protein MSH6 expression in NF-PitNETs has been suggested as a predictor of temozolomide effect in PitNETs [91]; however, other studies did not confirm that [88].

\section{Methodological limitations in the histopathological diagnostics of NF-PitNETs}

Immunohistochemistry is essential in the classification of pituitary tumors. It is a widely-used method in pathology because it can be highly sensitive and specific in protein detection on tissue slides, fast, relatively inexpensive, and can be automated. At the same time, different preanalytical conditions such as ischemic time and duration of fixation are difficult to control even in the standardized clinical laboratory settings. Immunohistochemical protocols require continuous optimization through internal and external validation; read-out of the immunohistochemical results is human-dependent and prone to subjective interpretation [92].

In the context of pituitary tumor pathology, the preanalytical factors can potentially affect the expression of adenohypophysial hormones. The combined use of antibodies toward the adenohypophysial hormone and transcription factors, at least in tumors with sparse hormone expression, can increase the accuracy in the phenotyping of PitNETs. However, experiences with the T-Pit antibody are limited in routine praxis as it has only recently been available, and the most often used anti SF-1 antibody, clone N1665, produces inconsistent results even in the laboratories with expertise within pituitary pathology. When it comes to the proliferative marker Ki-67, disagreement about the quantification method and a lack of the assessment recommendations are additional problems. Experience with the digital quantification of Ki-67 in clinical praxis is limited, but should be considered as a tool to reduce the intra- and inter-observer variations in the assessment [75].

\section{Conclusion}

Non-functioning pituitary tumors represent a heterogeneous group of PitNETs, whose precise histopathological classification depends upon detailed immunohistochemical evaluation of adenohypophysial hormone expression. Assessment of mitotic account, proliferative Ki-67 index, and tumor invasiveness is important to identify potentially aggressive tumors. Application of pituitary specific transcription factors plays an important role in recognition of less differentiated tumor types, some of which may demonstrate aggressive behavior. Predictive markers should be included in the classification, particularly when pharmacological therapy is under consideration. Further investigations are needed to recognize additional prognostic and predictive markers in clinically NF-PitNETs.

\section{Compliance with ethical standards}

Conflict of interest The authors declare that they have no competing interests.

Open Access This article is distributed under the terms of the Creative Commons Attribution 4.0 International License (http://creativecommons.org/licenses/by/4.0/), which permits unrestricted use, distribution, and reproduction in any medium, provided you give appropriate 
credit to the original author(s) and the source, provide a link to the Creative Commons license, and indicate if changes were made.

\section{References}

1. Asa SL, Casar-Borota O, Chanson P, Delgrange E, Earls P, Ezzat S, Grossman A, Ikeda H, Inoshita N, Karavitaki N, Korbonits M, Laws ER Jr, Lopes MB, Maartens N, McCutcheon IE, Mete O, Nishioka H, Raverot G, Roncaroli F, Saeger W, Syro LV, Vasiljevic A, Villa C, Wierinckx A, Trouillas J (2017) From pituitary adenoma to pituitary neuroendocrine tumor (PitNET): an International Pituitary Pathology Club proposal. Endocr Relat Cancer 24(4):C5-c8

2. Lloyd RV, Osamura RY, Kloppel G, Rosai J (2017) WHO classification of tumours of endocirne organs, 4th edn. International Agency for Research on Cancer, Lyon

3. Mayson SE, Snyder PJ (2014) Silent (clinically nonfunctioning) pituitary adenomas. J Neurooncol 117(3):429-436

4. Cooper O, Melmed S (2012) Subclinical hyperfunctioning pituitary adenomas: the silent tumors. Best Pract Res Clin Endocrinol Metab 26(4):447-460

5. Fernandez A, Karavitaki N, Wass JA (2010) Prevalence of pituitary adenomas: a community-based, cross-sectional study in Banbury (Oxfordshire, UK). Clin Endocrinol 72(3):377-382

6. Raappana A, Koivukangas J, Ebeling T, Pirila T (2010) Incidence of pituitary adenomas in Northern Finland in 1992-2007. J Clin Endocrinol Metab 95(9):4268-4275

7. Tjornstrand A, Gunnarsson K, Evert M, Holmberg E, Ragnarsson O, Rosen T, Nystrom HF (2014) The incidence rate of pituitary adenomas in western Sweden for the period 2001-2011. Eur J Endocrinol 171(4):519-526

8. Brochier S, Galland F, Kujas M, Parker F, Gaillard S, Raftopoulos C, Young J, Alexopoulou O, Maiter D, Chanson P (2010) Factors predicting relapse of nonfunctioning pituitary macroadenomas after neurosurgery: a study of 142 patients. Eur J Endocrinol 163(2):193-200

9. Sanmillan JL, Torres-Diaz A, Sanchez-Fernandez JJ, Lau R, Ciller C, Puyalto P, Gabarros A (2017) Radiological predictors for extent of resection in pituitary adenoma surgery. A single-center study. World Neurosurg 108:436-446

10. Reddy R, Cudlip S, Byrne JV, Karavitaki N, Wass JA (2011) Can we ever stop imaging in surgically treated and radiotherapy-naive patients with non-functioning pituitary adenoma? Eur J Endocrinol 165(5):739-744

11. Tampourlou M, Ntali G, Ahmed S, Arlt W, Ayuk J, Byrne JV, Chavda S, Cudlip S, Gittoes N, Grossman A, Mitchell R, O'Reilly MW, Paluzzi A, Toogood A, Wass JAH, Karavitaki N (2017) Outcome of nonfunctioning pituitary adenomas that regrow after primary treatment: a study from two large UK centers. J Clin Endocrinol Metab 102(6):1889-1897

12. Oystese KA, Evang JA, Bollerslev J (2016) Non-functioning pituitary adenomas: growth and aggressiveness. Endocrine 53(1):28-34

13. Oystese KA, Zucknick M, Casar-Borota O, Ringstad G, Bollerslev J (2017) Early postoperative growth in non-functioning pituitary adenomas; a tool to tailor safe follow-up. Endocrine 57(1):35-45

14. Peverelli E, Giardino E, Treppiedi D, Meregalli M, Belicchi M, Vaira V, Corbetta S, Verdelli C, Verrua E, Serban AL, Locatelli M, Carrabba G, Gaudenzi G, Malchiodi E, Cassinelli L, Lania AG, Ferrero S, Bosari S, Vitale G, Torrente Y, Spada A, Mantovani G (2017) Dopamine receptor type 2 (DRD2) and somatostatin receptor type 2 (SSTR2) agonists are effective in inhibiting proliferation of progenitor/stem-like cells isolated from nonfunctioning pituitary tumors. Int J Cancer 140(8):1870-1880
15. DeLellis RA (2004) Pathology and genetics of tumours of endocrine organs. World Health Organization classification of tumours, vol 8. International Agency for Research on Cancer, Lyon

16. Grossman AB (2006) The 2004 World Health Organization classification of pituitary tumors: is it clinically helpful? Acta Neuropathol 111(1):76-77

17. Castinetti F, Dufour H, Gaillard S, Jouanneau E, Vasiljevic A, Villa C, Trouillas J (2015) Non-functioning pituitary adenoma: when and how to operate? What pathologic criteria for typing? Ann Endocrinol 76(3):220-227

18. Sjostedt E, Bollerslev J, Mulder J, Lindskog C, Ponten F, CasarBorota O (2017) A specific antibody to detect transcription factor T-Pit: a reliable marker of corticotroph cell differentiation and a tool to improve the classification of pituitary neuroendocrine tumours. Acta Neuropathol 134(4):675-677

19. Trouillas J, Roy P, Sturm N, Dantony E, Cortet-Rudelli C, Viennet G, Bonneville JF, Assaker R, Auger C, Brue T, Cornelius A, Dufour H, Jouanneau E, Francois P, Galland F, Mougel F, Chapuis F, Villeneuve L, Maurage CA, Figarella-Branger D, Raverot G, Barlier A, Bernier M, Bonnet F, Borson-Chazot F, Brassier G, Caulet-Maugendre S, Chabre O, Chanson P, Cottier JF, Delemer B, Delgrange E, Di Tommaso L, Eimer S, Gaillard S, Jan M, Girard JJ, Lapras V, Loiseau H, Passagia JG, Patey M, Penfornis A, Poirier JY, Perrin G, Tabarin A (2013) A new prognostic clinicopathological classification of pituitary adenomas: a multicentric case-control study of 410 patients with 8 years post-operative follow-up. Acta Neuropathol 126(1):123-135

20. Raverot G, Dantony E, Beauvy J, Vasiljevic A, Mikolasek S, Borson-Chazot F, Jouanneau E, Roy P, Trouillas J (2017) Risk of recurrence in pituitary neuroendocrine tumors: a prospective study using a five-tiered classification. J Clin Endocrinol Metab 102:3368-3374

21. Lopes MBS (2017) The 2017 World Health Organization classification of tumors of the pituitary gland: a summary. Acta Neuropathol 134:521-535

22. McDonald WC, Banerji N, McDonald KN, Ho B, Macias V, Kajdacsy-Balla A (2017) Steroidogenic Factor 1, Pit-1, and adrenocorticotropic hormone: a rational starting place for the immunohistochemical characterization of pituitary adenoma. Arch Pathol Lab Med 141(1):104-112

23. Marques P, Korbonits M (2017) Genetic aspects of pituitary adenomas. Endocrinol Metab Clin North Am 46(2):335-374

24. Caimari F, Korbonits M (2016) Novel genetic causes of pituitary adenomas. Clin Cancer Res 22(20):5030-5042

25. Perez-Rivas LG, Theodoropoulou M, Ferrau F, Nusser C, Kawaguchi K, Stratakis CA, Faucz FR, Wildemberg LE, Assie G, Beschorner R, Dimopoulou C, Buchfelder M, Popovic V, Berr CM, Toth M, Ardisasmita AI, Honegger J, Bertherat J, Gadelha MR, Beuschlein F, Stalla G, Komada M, Korbonits M, Reincke M (2015) The gene of the ubiquitin-specific protease 8 is frequently mutated in adenomas causing Cushing's disease. J Clin Endocrinol Metab 100(7):E997-E1004

26. Denes J, Swords F, Rattenberry E, Stals K, Owens M, Cranston T, Xekouki P, Moran L, Kumar A, Wassif C, Fersht N, Baldeweg SE, Morris D, Lightman S, Agha A, Rees A, Grieve J, Powell M, Boguszewski CL, Dutta P, Thakker RV, Srirangalingam U, Thompson CJ, Druce M, Higham C, Davis J, Eeles R, Stevenson M, O’Sullivan B, Taniere P, Skordilis K, Gabrovska P, Barlier A, Webb SM, Aulinas A, Drake WM, Bevan JS, Preda C, Dalantaeva N, Ribeiro-Oliveira A Jr, Garcia IT, Yordanova G, Iotova V, Evanson J, Grossman AB, Trouillas J, Ellard S, Stratakis CA, Maher ER, Roncaroli F, Korbonits M (2015) Heterogeneous genetic background of the association of pheochromocytoma/paraganglioma and pituitary adenoma: results from a large patient cohort. J Clin Endocrinol Metab 100(3):E531-E541 
27. Scully KM, Rosenfeld MG (2002) Pituitary development: regulatory codes in mammalian organogenesis. Science 295(5563):2231-2235

28. Asa SL, Puy LA, Lew AM, Sundmark VC, Elsholtz HP (1993) Cell type-specific expression of the pituitary transcription activator pit-1 in the human pituitary and pituitary adenomas. J Clin Endocrinol Metab 77(5):1275-1280

29. Mete O, Gomez-Hernandez K, Kucharczyk W, Ridout R, Zadeh G, Gentili F, Ezzat S, Asa SL (2016) Silent subtype 3 pituitary adenomas are not always silent and represent poorly differentiated monomorphous plurihormonal Pit-1 lineage adenomas. Mod Pathol 29(2):131-142

30. Asa SL, Bamberger AM, Cao B, Wong M, Parker KL, Ezzat S (1996) The transcription activator steroidogenic factor-1 is preferentially expressed in the human pituitary gonadotroph. J Clin Endocrinol Metab 81(6):2165-2170

31. Lamolet B, Pulichino AM, Lamonerie T, Gauthier Y, Brue T, Enjalbert A, Drouin J (2001) A pituitary cell-restricted T box factor, Tpit, activates POMC transcription in cooperation with Pitx homeoproteins. Cell 104(6):849-859

32. Pulichino AM, Vallette-Kasic S, Tsai JP, Couture C, Gauthier Y, Drouin J (2003) Tpit determines alternate fates during pituitary cell differentiation. Genes Dev 17(6):738-747

33. Delgrange E, Vasiljevic A, Wierinckx A, Francois P, Jouanneau E, Raverot G, Trouillas J (2015) Expression of estrogen receptor alpha is associated with prolactin pituitary tumor prognosis and supports the sex-related difference in tumor growth. Eur J Endocrinol 172(6):791-801

34. Friend KE, Chiou YK, Lopes MB, Laws ER Jr, Hughes KM, Shupnik MA (1994) Estrogen receptor expression in human pituitary: correlation with immunohistochemistry in normal tissue, and immunohistochemistry and morphology in macroadenomas. J Clin Endocrinol Metab 78(6):1497-1504

35. Oystese KA, Casar-Borota O, Normann KR, Zucknick M, Berg JP, Bollerslev J (2017) Estrogen receptor alpha, a sex-dependent predictor of aggressiveness in nonfunctioning pituitary adenomas: SSTR and sex hormone receptor distribution in NFPA. J Clin Endocrinol Metab 102(9):3581-3590

36. Yamada S, Ohyama K, Taguchi M, Takeshita A, Morita K, Takano K, Sano T (2007) A study of the correlation between morphological findings and biological activities in clinically nonfunctioning pituitary adenomas. Neurosurgery 61(3):580-584

37. Saeger W, Ludecke DK, Buchfelder M, Fahlbusch R, Quabbe HJ, Petersenn S (2007) Pathohistological classification of pituitary tumors: 10 years of experience with the German Pituitary Tumor Registry. Eur J Endocrinol 156(2):203-216

38. Mayson SE, Snyder PJ (2015) Silent pituitary adenomas. Endocrinol Metab Clin North Am 44(1):79-87

39. Korbonits M, Carlsen E (2009) Recent clinical and pathophysiological advances in non-functioning pituitary adenomas. Horm Res 71(Suppl 2):123-130

40. Cooper O (2015) Silent corticotroph adenomas. Pituitary 18(2):225-231

41. Raverot G, Wierinckx A, Jouanneau E, Auger C, Borson-Chazot F, Lachuer J, Pugeat M, Trouillas J (2010) Clinical, hormonal and molecular characterization of pituitary ACTH adenomas without (silent corticotroph adenomas) and with Cushing's disease. Eur J Endocrinol 163(1):35-43

42. Scheithauer BW, Jaap AJ, Horvath E, Kovacs K, Lloyd RV, Meyer FB, Laws ER Jr, Young WF Jr (2000) Clinically silent corticotroph tumors of the pituitary gland. Neurosurgery 47(3):723-729

43. Giri D, Roncaroli F, Sinha A, Didi M, Senniappan S (2017) Silent Crooke's cell corticotroph adenoma of the pituitary gland presenting as delayed puberty. Endocrinol Diabetes Metab Case Rep. https://doi.org/10.1530/edm-16-0153
44. Zoli M, Faustini-Fustini M, Mazzatenta D, Marucci G, De Carlo E, Bacci A, Pasquini E, Lanzino G, Frank G (2015) ACTH adenomas transforming their clinical expression: report of 5 cases. Neurosurg Focus 38(2):E15

45. Righi A, Faustini-Fustini M, Morandi L, Monti V, Asioli S, Mazzatenta D, Bacci A, Foschini MP (2017) The changing faces of corticotroph cell adenomas: the role of prohormone convertase 1/3. Endocrine 56(2):286-297

46. Baldeweg SE, Pollock JR, Powell M, Ahlquist J (2005) A spectrum of behaviour in silent corticotroph pituitary adenomas. Br J Neurosurg 19(1):38-42

47. Tateno $\mathrm{T}$, Izumiyama $\mathrm{H}$, Doi $\mathrm{M}$, Akashi $\mathrm{T}$, Ohno K, Hirata $\mathrm{Y}$ (2007) Defective expression of prohormone convertase $1 / 3$ in silent corticotroph adenoma. Endocr J 54(5):777-782

48. Tateno T, Izumiyama H, Doi M, Yoshimoto T, Shichiri M, Inoshita N, Oyama K, Yamada S, Hirata Y (2007) Differential gene expression in $\mathrm{ACTH}$-secreting and non-functioning pituitary tumors. Eur J Endocrinol 157(6):717-724

49. Ohta S, Nishizawa S, Oki Y, Yokoyama T, Namba H (2002) Significance of absent prohormone convertase $1 / 3$ in inducing clinically silent corticotroph pituitary adenoma of subtype I-immunohistochemical study. Pituitary 5(4):221-223

50. Jahangiri A, Wagner JR, Pekmezci M, Hiniker A, Chang EF, Kunwar S, Blevins L, Aghi MK (2013) A comprehensive longterm retrospective analysis of silent corticotrophic adenomas vs hormone-negative adenomas. Neurosurgery 73(1):8-17

51. Webb KM, Laurent JJ, Okonkwo DO, Lopes MB, Vance ML, Laws ER Jr (2003) Clinical characteristics of silent corticotrophic adenomas and creation of an internet-accessible database to facilitate their multi-institutional study. Neurosurgery 53(5):1076-1084

52. Wade AN, Baccon J, Grady MS, Judy KD, O'Rourke DM, Snyder PJ (2011) Clinically silent somatotroph adenomas are common. Eur J Endocrinol 165(1):39-44

53. Chinezu L, Vasiljevic A, Trouillas J, Lapoirie M, Jouanneau E, Raverot G (2017) Silent somatotroph tumour revisited from a study of 80 patients with and without acromegaly and a review of the literature. Eur J Endocrinol 176(2):195-201

54. Obari A, Sano T, Ohyama K, Kudo E, Qian ZR, Yoneda A, Rayhan N, Rahman MM, Yamada S (2008) Clinicopathological features of growth hormone-producing pituitary adenomas: difference among various types defined by cytokeratin distribution pattern including a transitional form. Endocr Pathol 19(2):82-91

55. Fougner SL, Casar-Borota O, Heck A, Berg JP, Bollerslev J (2012) Adenoma granulation pattern correlates with clinical variables and effect of somatostatin analogue treatment in a large series of patients with acromegaly. Clin Endocrinol 76(1):96-102

56. Kato M, Inoshita N, Sugiyama T, Tani Y, Shichiri M, Sano T, Yamada S, Hirata Y (2012) Differential expression of genes related to drug responsiveness between sparsely and densely granulated somatotroph adenomas. Endocr J 59(3):221-228

57. Karavitaki N, Thanabalasingham G, Shore HC, Trifanescu R, Ansorge O, Meston N, Turner HE, Wass JA (2006) Do the limits of serum prolactin in disconnection hyperprolactinaemia need re-definition? A study of 226 patients with histologically verified non-functioning pituitary macroadenoma. Clin Endocrinol 65(4):524-529

58. Buurman H, Saeger W (2006) Subclinical adenomas in postmortem pituitaries: classification and correlations to clinical data. Eur J Endocrinol 154(5):753-758

59. Noronha S, Stokes V, Karavitaki N, Grossman A (2016) Treating prolactinomas with dopamine agonists: always worth the gamble? Endocrine 51(2):205-210

60. Bertholon-Gregoire M, Trouillas J, Guigard MP, Loras B, Tourniaire J (1999) Mono- and plurihormonal thyrotropic pituitary 
adenomas: pathological, hormonal and clinical studies in 12 patients. Eur J Endocrinol 140(6):519-527

61. Azzalin A, Appin CL, Schniederjan MJ, Constantin T, Ritchie JC, Veledar E, Oyesiku NM, Ioachimescu AG (2016) Comprehensive evaluation of thyrotropinomas: single-center 20-year experience. Pituitary 19(2):183-193

62. Kirkman MA, Jaunmuktane Z, Brandner S, Khan AA, Powell M, Baldeweg SE (2014) Active and silent thyroid-stimulating hormone-expressing pituitary adenomas: presenting symptoms, treatment, outcomes, and recurrence. World Neurosurg 82(6):1224-1231

63. Onnestam L, Berinder K, Burman P, Dahlqvist P, Engstrom BE, Wahlberg J, Nystrom HF (2013) National incidence and prevalence of TSH-secreting pituitary adenomas in Sweden. J Clin Endocrinol Metab 98(2):626-635

64. Daems T, Verhelst J, Michotte A, Abrams P, De Ridder D, Abs $R$ (2009) Modification of hormonal secretion in clinically silent pituitary adenomas. Pituitary 12(1):80-86

65. Casar-Borota O, Botling J, Granberg D, Stigare J, Wikstrom J, Boldt HB, Kristensen BW, Ponten F, Trouillas J (2017) Serotonin, ATRX, and DAXX expression in pituitary adenomas: markers in the differential diagnosis of neuroendocrine tumors of the sellar region. Am J Surg Pathol 41(9):1238-1246

66. Horvath E, Kovacs K, Smyth HS, Killinger DW, Scheithauer BW, Randall R, Laws ER Jr, Singer W (1988) A novel type of pituitary adenoma: morphological features and clinical correlations. J Clin Endocrinol Metab 66(6):1111-1118

67. Horvath E, Kovacs K, Smyth HS, Cusimano M, Singer W (2005) Silent adenoma subtype 3 of the pituitary-immunohistochemical and ultrastructural classification: a review of 29 cases. Ultrastruct Pathol 29(6):511-524

68. Erickson D, Scheithauer B, Atkinson J, Horvath E, Kovacs K, Lloyd RV, Young WF Jr (2009) Silent subtype 3 pituitary adenoma: a clinicopathologic analysis of the Mayo Clinic experience. Clin Endocrinol 71(1):92-99

69. Kontogeorgos G, Scheithauer BW, Horvath E, Kovacs K, Lloyd RV, Smyth HS, Rologis D (1992) Double adenomas of the pituitary: a clinicopathological study of 11 tumors. Neurosurgery 31(5):840-849

70. Kontogeorgos G, Kovacs K, Horvath E, Scheithauer BW (1991) Multiple adenomas of the human pituitary. A retrospective autopsy study with clinical implications. J Neurosurg 74(2):243-247

71. Chan DL, Clarke SJ, Diakos CI, Roach PJ, Bailey DL, Singh S, Pavlakis N (2017) Prognostic and predictive biomarkers in neuroendocrine tumours. Crit Rev Oncol Hematol 113:268-282

72. Jaffrain-Rea ML, Di Stefano D, Minniti G, Esposito V, Bultrini A, Ferretti E, Santoro A, Scucchi LF, Gulino A, Cantore G (2002) A critical reappraisal of MIB-1 labelling index significance in a large series of pituitary tumours: secreting versus non-secreting adenomas. Endocr Relat Cancer 9(2):103-113

73. Chiloiro S, Bianchi A, Doglietto F, de Waure C, Giampietro A, Fusco A, Iacovazzo D, Tartaglione L, Di Nardo F, Signorelli F, Lauriola L, Anile C, Rindi G, Maira G, Pontecorvi A, De Marinis L (2014) Radically resected pituitary adenomas: prognostic role of Ki 67 labeling index in a monocentric retrospective series and literature review. Pituitary 17(3):267-276

74. Miermeister CP, Petersenn S, Buchfelder M, Fahlbusch R, Ludecke DK, Holsken A, Bergmann M, Knappe HU, Hans VH, Flitsch J, Saeger W, Buslei R (2015) Histological criteria for atypical pituitary adenomas - data from the German pituitary adenoma registry suggests modifications. Acta Neuropathol Commun 3:50

75. Righi A, Agati P, Sisto A, Frank G, Faustini-Fustini M, Agati R, Mazzatenta D, Farnedi A, Menetti F, Marucci G, Foschini MP (2012) A classification tree approach for pituitary adenomas. Hum Pathol 43(10):1627-1637
76. Zhou Y, Zhang X, Klibanski A (2014) Genetic and epigenetic mutations of tumor suppressive genes in sporadic pituitary adenoma. Mol Cell Endocrinol 386(1-2):16-33

77. Thapar K, Scheithauer BW, Kovacs K, Pernicone PJ, Laws ER Jr (1996) p53 expression in pituitary adenomas and carcinomas: correlation with invasiveness and tumor growth fractions. Neurosurgery 38(4):765-770

78. Madsen H, Borges TM, Knox AJ, Michaelis KA, Xu M, Lillehei KO, Wierman ME, Kleinschmidt-DeMasters BK (2011) Giant pituitary adenomas: pathologic-radiographic correlations and lack of role for p53 and MIB-1 labeling. Am J Surg Pathol 35(8):1204-1213

79. Saeger W, Ludecke B, Ludecke DK (2008) Clinical tumor growth and comparison with proliferation markers in non-functioning (inactive) pituitary adenomas. Exp Clin Endocrinol Diabetes 116(2):80-85

80. Zhou W, Song Y, Xu H, Zhou K, Zhang W, Chen J, Qin M, Yi H, Gustafsson JA, Yang H, Fan X (2011) In nonfunctional pituitary adenomas, estrogen receptors and slug contribute to development of invasiveness. J Clin Endocrinol Metab 96(8):E1237-E1245

81. Dai C, Sun B, Liu X, Bao X, Feng M, Yao Y, Wei J, Deng K, Yang C, Li X, Ma W, Wang R (2017) $O$-6-Methylguanine-DNA methyltransferase expression is associated with pituitary adenoma tumor recurrence: a systematic meta-analysis. Oncotarget 8(12):19674-19683

82. Farrell WE, Coll AP, Clayton RN, Harris PE (2003) Corticotroph carcinoma presenting as a silent corticotroph adenoma. Pituitary $6(1): 41-47$

83. Kaltsas GA, Nomikos P, Kontogeorgos G, Buchfelder M, Grossman AB (2005) Clinical review: diagnosis and management of pituitary carcinomas. J Clin Endocrinol Metab 90(5):3089-3099

84. Lee M, Lupp A, Mendoza N, Martin N, Beschorner R, Honegger J, Schlegel J, Shively T, Pulz E, Schulz S, Roncaroli F, Pellegata NS (2015) SSTR3 is a putative target for the medical treatment of gonadotroph adenomas of the pituitary. Endocr Relat Cancer 22(1):111-119

85. Iacovazzo D, Carlsen E, Lugli F, Chiloiro S, Piacentini S, Bianchi A, Giampietro A, Mormando M, Clear AJ, Doglietto F, Anile C, Maira G, Lauriola L, Rindi G, Roncaroli F, Pontecorvi A, Korbonits M, De Marinis L (2016) Factors predicting pasireotide responsiveness in somatotroph pituitary adenomas resistant to first-generation somatostatin analogues: an immunohistochemical study. Eur J Endocrinol 174(2):241-250

86. Neto LV, Machado Ede O, Luque RM, Taboada GF, Marcondes JB, Chimelli LM, Quintella LP, Niemeyer P Jr, de Carvalho DP, Kineman RD, Gadelha MR (2009) Expression analysis of dopamine receptor subtypes in normal human pituitaries, nonfunctioning pituitary adenomas and somatotropinomas, and the association between dopamine and somatostatin receptors with clinical response to octreotide-LAR in acromegaly. J Clin Endocrinol Metab 94(6):1931-1937

87. Greenman Y, Cooper O, Yaish I, Robenshtok E, Sagiv N, JonasKimchi T, Yuan X, Gertych A, Shimon I, Ram Z, Melmed S, Stern $\mathrm{N}$ (2016) Treatment of clinically nonfunctioning pituitary adenomas with dopamine agonists. Eur J Endocrinol 175(1):63-72

88. Bengtsson D, Schroder HD, Andersen M, Maiter D, Berinder K, Feldt Rasmussen U, Rasmussen AK, Johannsson G, Hoybye C, van der Lely AJ, Petersson M, Ragnarsson O, Burman P (2015) Long-term outcome and MGMT as a predictive marker in 24 patients with atypical pituitary adenomas and pituitary carcinomas given treatment with temozolomide. J Clin Endocrinol Metab 100(4):1689-1698

89. Bush ZM, Longtine JA, Cunningham T, Schiff D, Jane JA Jr, Vance ML, Thorner MO, Laws ER Jr, Lopes MB (2010) Temozolomide treatment for aggressive pituitary tumors: correlation of clinical outcome with $O(6)$-methylguanine methyltransferase 
(MGMT) promoter methylation and expression. J Clin Endocrinol Metab 95(11):E280-E290

90. Halevy C, Whitelaw BC (2017) How effective is temozolomide for treating pituitary tumours and when should it be used? Pituitary 20(2):261-266

91. Hirohata T, Asano K, Ogawa Y, Takano S, Amano K, Isozaki O, Iwai Y, Sakata K, Fukuhara N, Nishioka H, Yamada S, Fujio S, Arita K, Takano K, Tominaga A, Hizuka N, Ikeda H, Osamura RY, Tahara S, Ishii Y, Kawamata T, Shimatsu A, Teramoto A, Matsuno A (2013) DNA mismatch repair protein (MSH6) correlated with the responses of atypical pituitary adenomas and pituitary carcinomas to temozolomide: the national cooperative study by the Japan Society for Hypothalamic and Pituitary Tumors. J Clin Endocrinol Metab 98(3):1130-1136

92. Torlakovic EE, Cheung CC, D’Arrigo C, Dietel M, Francis GD, Gilks CB, Hall JA, Hornick JL, Ibrahim M, Marchetti A, Miller K, van Krieken JH, Nielsen S, Swanson PE, Vyberg M, Zhou X, Taylor CR (2017) Evolution of quality assurance for clinical immunohistochemistry in the era of precision medicine. Part 3: technical validation of immunohistochemistry (IHC) assays in clinical IHC laboratories. Appl Immunohistochem Mol Morphol 25(3):151-159 